\title{
BCG Vaccination and Mortality of COVID-19 across 173 Countries: An Ecological Study
}

\author{
Mitsuyoshi Urashima ${ }^{1, * \mathbb{C}}$, Katharina Otani ${ }^{1,2} \mathbb{D}$, Yasutaka Hasegawa ${ }^{1,3}$ and Taisuke Akutsu ${ }^{1}$ \\ 1 Division of Molecular Epidemiology, The Jikei University School of Medicine, Tokyo 105-8461, Japan; \\ katharina@jikei.ac.jp (K.O.); yhearth102523@jikei.ac.jp (Y.H.); t-akutsu@jikei.ac.jp (T.A.) \\ 2 Advanced Therapies Innovation Department, Siemens Healthcare K.K., Tokyo 141-8644, Japan; \\ katharina.otani@siemens-healthineers.com \\ 3 Hitachi, Ltd. Research \& Development Group, Tokyo 185-8601, Japan; yasutaka.hasegawa.mp@hitachi.com \\ * $\quad$ Correspondence: urashima@jikei.ac.jp; Tel.: +81-3-3433-1111 (ext. 2405)
}

Received: 4 July 2020; Accepted: 31 July 2020; Published: 3 August 2020

check for updates

\begin{abstract}
Ecological studies have suggested fewer COVID-19 morbidities and mortalities in Bacillus Calmette-Guérin (BCG)-vaccinated countries than BCG-non-vaccinated countries. However, these studies obtained data during the early phase of the pandemic and did not adjust for potential confounders, including PCR-test numbers per population (PCR-tests). Currently-more than four months after declaration of the pandemic - the BCG-hypothesis needs reexamining. An ecological study was conducted by obtaining data of 61 factors in 173 countries, including BCG vaccine coverage (\%), using morbidity and mortality as outcomes, obtained from open resources. 'Urban population (\%)' and 'insufficient physical activity (\%)' in each country was positively associated with morbidity, but not mortality, after adjustment for PCR-tests. On the other hand, recent BCG vaccine coverage (\%) was negatively associated with mortality, but not morbidity, even with adjustment for percentage of the population $\geq 60$ years of age, morbidity, PCR-tests and other factors. The results of this study generated a hypothesis that a national BCG vaccination program seems to be associated with reduced mortality of COVID-19, although this needs to be further examined and proved by randomized clinical trials.
\end{abstract}

Keywords: urbanization; Bacillus Calmette-Guérin; BCG; vaccination; coronavirus disease 2019; COVID-19; SARS-CoV-2; ecological study; morbidity; mortality

\section{Introduction}

Currently, more than four months since declaration of the coronavirus disease 2019 (COVID-19) as a pandemic by the World Health Organization (WHO) on March 11th, 2020, more than 14 million people have been infected with the virus and more than half a million have died worldwide. Marked differences in COVID-19 mortalities have been observed in different countries. For example, the mortality per million population is till now several tens of times or even higher in Western countries, e.g., Belgium (845), the United Kingdom (UK, 664), the United States of America (USA, 426) and Germany (109), than in Asian countries, e.g., India (19), Japan (8) and China (3), as of 17 July 2020. This is quite the opposite of what was reported during the 1918-20 influenza pandemic, the so called Spanish flu, in which the population mortality was over 30-fold higher, with excess death rates observed in low-income countries, such as India, than in high-income countries, such as those in the West [1]. Higher morbidities and mortalities may be explained by easy access to diagnostic polymerase chain reaction tests (PCR-tests) for severe acute respiratory syndrome coronavirus 2 (SARS-CoV-2) in these Western countries. In contrast, they may be underestimated in middle- and low-income countries due to low capacities of PCR-testing and poor access to health care. Alternatively, there is growing concern 
that racial and ethnic minority, as well as socioeconomic and biological factors may influence the high morbidity and mortality. A retrospective study of integrated health care systems suggested that Black race compared with White race, increasing age, male sex, having a greater burden of comorbidities, type of public insurance, residence in a low-income area and obesity were associated with increased odds of hospital admission [2]. On the other hand risk of in-hospital mortality increased only in aged patients and was not associated with the Black race, sex, comorbidities, obesity and other factors after multivariate adjustment [2]; this phenomenon was also confirmed in other races, i.e., Asians and Hispanics, compared with the White race [3,4]. Moreover, since COVID-19 is an infectious disease that spreads mainly through the droplet route by close contact in dense human societies, metropolitan areas, such as New York City in the USA [5] and Lombardy in Italy [6], Paris in France [7], Sao Paulo in Brazil [8], and so on, have tended to be regional epicenters. However, associations between population dynamics, e.g., population size, density, migrants and urbanization and the morbidity/mortality of COVID-19 have not yet been well examined.

In addition to the factors listed above, several scientists proposed a hypothesis [9-12] that Bacillus Calmette-Guérin (BCG) vaccination has preventive effects not only against tuberculosis, i.e., the target disease of the vaccine, but also other non-specific infectious diseases, i.e., off-target diseases such as COVID-19, through epigenetic mechanisms [13-15]. In fact, ecological studies have suggested that both COVID-19 morbidities and mortalities were less in BCG-vaccinated countries than in BCG-non-vaccinated countries [16-18]. However, because these studies only obtained data during the early phase of the pandemic, by which time the disease load had escalated in Western countries, but not yet escalated in low- and middle-income countries where BCG is given at birth and did not adjust for any potential confounders, including PCR-test number per million population, the BCG-hypothesis needs to be reexamined now, more than four months after declaration of the pandemic, since the number of PCR-confirmed COVID-19 cases are still growing in many countries. We therefore aimed to explore whether recent BCG vaccine coverage is associated with COVID-19 morbidity and/or mortality rates, using linear regression models to explore associations between the two continuous random variables adjusted for a variety of potential confounders, such as median age and body mass index (BMI) in individual countries through this ecological study.

\section{Materials and Methods}

\subsection{Ethics Statement}

Institutional review board approval for this work was not sought due to the use of publicly available data obtained from open resources.

\subsection{Study Design}

This ecological study compared population data of each country.

\subsection{Data Resources}

All data were obtained from open resources: Information on total number of cases, total number of deaths and number of PCR-tests performed per million population were obtained from 'Coronavirus Update' [19], data regarding population dynamics were obtained from 'World Population Clock' [20], socioeconomic covariates were obtained from 'the United Nations database' [21], BCG vaccine coverage data were obtained from 'The BCG World Atlas' [22] and 'The global health observatory' on the WHO homepage [18] and other health related data were from the same WHO site [23]. Definitions of each of the covariates are described in the Supplement. Only countries that had data of both total deaths and BCG vaccine coverage were included for analyses in this study. 


\subsection{Outcomes and PCR-Tests}

The outcomes evaluated in this study were COVID-19 morbidity, i.e., total COVID-19 cases per million population and COVID-19 mortality, i.e., total COVID-19-related deaths per million population, in each country, obtained from 'Worldometer COVID-19 Data' on July 17th, 2020 [19]. Data on the total number of PCR-tests performed per million population were simultaneously obtained from the same 'Worldometer COVID-19 Data' website. PCR-test positivity was simply calculated as the total COVID-19 case number divided by the total number of PCR-tests performed in each country.

\subsection{BCG Vaccine Coverage}

Recent BCG vaccine coverage was defined as the percentage of the vaccinated population among one-year-olds in each country (World Health Data Platform, the World Health Observatory, BCG-Immunization coverage estimates) [23]. For countries that have already stopped a national BCG vaccine immunization program [22], which includes a significant number of countries, their BCG vaccine coverage rate was counted as zero percent in this study.

\subsection{Sixty-One Covariates}

The covariates evaluated in this study, the definitions of which are described in the Supplement (Table S1), included: (1) Population (n); (2) yearly change in population (\%); (3) net change in population (n); (4) population density $\left(\mathrm{n} / \mathrm{km}^{2}\right)$; (5) land area $\left(\mathrm{km}^{2}\right)$; (6) net number of migrants $(\mathrm{n})$; (7) fertility rate (n); (8) median age (years); (9) urban population percentage (\%); (10) world share (\%); (11) population between age 0 to 14 years (\%); (12) population $\geq 60$ years of age (\%); (13) population $\geq 70$ years of age (\%); (14) gross domestic product (GDP) (million US dollars); (15) GDP per capita (US dollars); (16) total unemployment rate (\%); (17) male unemployment rate (\%); (18) female unemployment rate (\%); (19) total labor force participation rate (\%); (20) male labor force participation rate (\%); (21) female labor force participation rate (\%); (22) annual incidence of tuberculosis per 100,000 population (n); (23) international health regulation (IHR) score (\%); (24) universal health coverage (UHC) index; (25) hospital beds (n) per 10,000 population; (26) medical doctors (n) per 10,000 population; (27) nursing midwifery (n) per 10,000 population; (28) licensed qualified anesthesiologists who usually cover management of intensive care units actively working (n) per 10,000 population; (29) total expenditure on health as a percentage of GDP (\%); (30) population with household expenditures on health greater than $10 \%$ of total household expenditure or income (\%); (31) prevalence of high blood pressure (systolic $\geq 140$ or diastolic $\geq 90 \mathrm{mmHg}$ ) (\%); (32) prevalence of elevated fasting blood glucose levels $(\geq 7.0 \mathrm{mmol} / \mathrm{L}$ or on anti-diabetic medication); (33) prevalence of elevated total cholesterol levels ( $\geq 5.0 \mathrm{mmol} / \mathrm{L})(\%)$; (34) mean BMI (body weight $[\mathrm{kg}] /$ height $^{2}\left[\mathrm{~m}^{2}\right]$ ); (35) prevalence of obesity among adults, BMI $\geq 30 \mathrm{~kg} / \mathrm{m}^{2}(\%)$; (36) prevalence of 'overweight' people among adults, $\mathrm{BMI} \geq 25 \mathrm{~kg} / \mathrm{m}^{2}$ (\%); (37) alcohol drinking, total per capita ( $\geq 15$ years of age) consumption (in liters of pure alcohol over a calendar year); (38) prevalence of smoking any tobacco product among males aged $\geq 15$ years (\%); (39) prevalence of smoking any tobacco product among females aged $\geq 15$ years (\%); (40) prevalence of insufficient physical activity among adults aged $\geq 18$ years (\%); (41) estimated population-based prevalence of depression (\%); (42) neonatal mortality rate (n per 1000 live births); (43) infantile mortality rate (n per 1000 live births); (44) under-five mortality rate (probability of dying by the age of 5 years per 1000 live births); (45) mortality rate for 5-14-year-olds (probability of dying per 1000 children aged 5-14 years); (46) adult mortality rate (probability of dying between 15 and 60 years of age per 1000 population); (47) probability of dying between age 30 and exact age 70 years from any of the following causes: cardiovascular disease, cancer, diabetes or chronic respiratory disease; (48) life expectancy at birth (years); (49) life expectancy at age 60 years (years); (50) healthy life expectancy (HALE) at birth (years); (51) HALE at age 60 years (years); (52) death due to chronic obstructive pulmonary disease (\%); (53) death due to ischemic heart disease (\%); (54) death due to lower respiratory infections (\%); (55) death due to stroke (\%); (56) death due to tracheal, bronchial 
and lung cancers (\%); (57) total of (52) to (56) as ambient and household air pollution-attributable death rate (n per 100,000 population); and (58) annual mean concentration of particulate matter less than 2.5 microns in diameter $\left(\mathrm{PM}_{2.5}\right)\left[\mu \mathrm{g} / \mathrm{m}^{3}\right]$ in urban areas; and (59) coverage rate with the first dose of a measles-containing-vaccine (MCV1) among one-year-olds (\%) as well as (60) recent BCG coverage and (61) PCR-tests number.

\subsection{Statistics}

\section{Linear Regression Models}

For preprocessed data, outcomes, i.e., morbidity and mortality per million population were transformed to the common logarithm $(\log 10)$ to adjust for normality of the distribution, which was verified by means of kurtosis tests. When the number of total deaths was zero, these were changed to 0.01 per million population, because zero cannot be transformed to the common logarithm. Variance inflation factor (VIF) was used to detect the presence of multicollinearity. Only one variable among biologically similar variables, e.g., 'median age (years)', ' $\geq 60$ years of age (\%)' and ' $\geq 70$ years of age', was selected to maximize adjusted $\mathrm{R}^{2}$ in the multi-linear regression models to avoid the influence of collinearity. If the variance inflation factor (VIF) of certain covariates was more than 10, then the covariates were avoided in multivariate analyses because of a collinearity issue. Multiple linear regression models were used to screen potential risk or preventive factors associated with morbidity by adjusting for PCR-test numbers transformed to the common logarithm $(\log 10)$ and those associated with mortality were screened by adjusting for PCR-test numbers and morbidity per million population. Considering type I error due to a multiple testing, the significance level of alfa was set as $p<0.001$. Then, all the screened factors were assessed in a multi-linear regression model to determine significant factors with $p<0.05$ as the cutoff point. Each model was evaluated by adjusted $\mathrm{R}^{2}$ as a coefficient of determination. Pearson's correlation coefficient for variables with normal distributions or Spearman's rank correlation for variables with non-normal distributions, represented as rho, was used to quantify the strengths of associations between morbidity, mortality and significant factors determined by the final models, as: absolute value of rho $\geq 0.5$ : very strong; rho $\geq 0.4$ : strong; $0.4>$ rho $\geq 0.2$ : moderate; and rho < 0.2: weak associations. Data were analyzed using Stata version 14.0 software (StataCorp LP, College Station, TX, USA).

\section{Results}

\subsection{Variability of COVID-19 Morbidity and Mortality across 173 Countries}

A total of 173 countries that had data of both total COVID-19 deaths and BCG vaccine coverage were included for analyses in this study. The 20 countries with highest and lowest COVID-19 morbidities (Table 1) and mortalities (Table 2), as well as their PCR-test rate per million population are shown below. Marked differences in morbidities and mortalities were observed among these countries, ranging from 1 (Papua New Guinea) to 37,566 (Qatar) and from 0 (Vietnam, etc.) to 845 (Belgium), respectively. Six and thirteen countries that do not have a BCG national vaccine program at present (indicated with bold and mark " ") were included in the 20 countries with the highest COVID-19 morbidity and mortality, respectively. 
Table 1. Twenty countries with the highest and lowest COVID-19 morbidity rates and their PCR-test rate per million population.

\begin{tabular}{|c|c|c|c|c|c|c|c|}
\hline \multicolumn{4}{|c|}{ The Highest 20 Countries } & \multicolumn{4}{|c|}{ The Lowest 20 Countries } \\
\hline Rank & Country & Morbidity * & PCR-Test * & Rank & Country * & Morbidity * & PCR-Test * \\
\hline 1 & Qatar & 37,566 & 153,380 & 173 & $\begin{array}{l}\text { Papua New Guinea } \\
\text { Lao People's }\end{array}$ & 1 & 798 \\
\hline 2 & Chile & 16,927 & 70,696 & 172 & $\begin{array}{c}\text { Democratic } \\
\text { Republic }\end{array}$ & 3 & 2990 \\
\hline 3 & Kuwait & 13,496 & 105,205 & 171 & Vietnam & 4 & 2824 \\
\hline 4 & Oman & 12,244 & 50,512 & 170 & Myanmar & 6 & 1770 \\
\hline 5 & Panama & 11,406 & 40,384 & 169 & $\begin{array}{l}\text { United Republic of } \\
\text { Tanzania }\end{array}$ & 9 & \\
\hline 6 & Armenia & 11,324 & 47,718 & 168 & Cambodia & 10 & 2896 \\
\hline 7 & Andorra $\int$ & 11,156 & 48,531 & 167 & Angola & 18 & 304 \\
\hline 8 & USA $\int$ & 11,118 & 137,544 & 166 & Timor-Leste & 18 & 1189 \\
\hline 9 & Peru & 10,355 & 60,747 & 165 & Taiwan & 19 & 3319 \\
\hline 10 & Brazil & 9464 & 23,098 & 164 & Uganda & 23 & 5133 \\
\hline 11 & Luxembourg $\int$ & 8438 & 502,852 & 163 & Burundi & 23 & 563 \\
\hline 12 & Singapore & 8053 & 172,506 & 162 & $\begin{array}{l}\text { Syrian Arab } \\
\text { Republic }\end{array}$ & 27 & \\
\hline 13 & Sweden $\int$ & 7610 & 67,495 & 161 & Fiji & 29 & 4461 \\
\hline 14 & Saudi Arabia & 6983 & 71,623 & 160 & Gambia & 32 & 1477 \\
\hline 15 & Belarus & 6945 & 123,003 & 159 & Mozambique & 44 & 1360 \\
\hline 16 & Spain $\int$ & 6543 & 128,893 & 158 & Niger & 45 & 276 \\
\hline 17 & UAE & 5673 & 436,262 & 157 & Thailand & 46 & 8647 \\
\hline 18 & South Africa & 5464 & 39,182 & 156 & Burkina Faso & 50 & \\
\hline 19 & Belgium $\int$ & 5438 & 121,891 & 155 & Yemen & 52 & 4 \\
\hline 20 & Maldives & 5234 & 118,769 & 154 & Chad & 54 & \\
\hline
\end{tabular}

* Numbers per million population, USA-United States of America, UAE-United Arab Emirates. Bold letters with mark " " mean no recent national BCG vaccination program for all.

Table 2. Twenty countries with the highest and lowest COVID-19 mortality rates and their PCR-test rates per million population.

\begin{tabular}{|c|c|c|c|c|c|c|c|}
\hline \multicolumn{4}{|c|}{ The Highest 20 Countries } & \multicolumn{4}{|c|}{ The Lowest 20 Countries } \\
\hline Rank & Country & Mortality * & PCR-Test * & Rank & Country * & Mortality * & PCR-Test * \\
\hline 1 & Belgium $\int$ & 845 & 121,891 & 173 & Papua New Guinea & 0 & 798 \\
\hline 2 & Andorra $\int$ & 673 & 48,531 & 172 & $\begin{array}{l}\text { Lao People's } \\
\text { Democratic } \\
\text { Republic }\end{array}$ & 0 & 2990 \\
\hline 3 & UK $\int$ & 664 & 186,591 & 171 & Vietnam & 0 & 2824 \\
\hline 4 & Spain & 608 & 128,893 & 170 & Cambodia & 0 & 2896 \\
\hline 5 & Italy $\int$ & 579 & 100,954 & 169 & Timor-Leste & 0 & 1189 \\
\hline 6 & Sweden $\int$ & 554 & 67,495 & 168 & Uganda & 0 & 5133 \\
\hline 7 & France $\int$ & 462 & 39,868 & 167 & Fiji & 0 & 4461 \\
\hline 8 & USA $\int$ & 426 & 137,544 & 166 & Eritrea & 0 & \\
\hline 9 & Peru & 382 & 60,747 & 165 & Mongolia & 0 & 8688 \\
\hline 10 & Chile & 381 & 70,696 & 164 & Bhutan & 0 & 51,107 \\
\hline 11 & Brazil & 361 & 23,098 & 163 & Saint Lucia & 0 & 11,494 \\
\hline 12 & Netherlands $\int$ & 358 & 44,588 & 162 & Greenland & 0 & 90,957 \\
\hline 13 & Ireland $\int$ & 354 & 107,707 & 161 & Dominica & 0 & 11,820 \\
\hline 14 & Ecuador $\int$ & 295 & 11,023 & 160 & $\begin{array}{l}\text { Saint Vincent and } \\
\text { the Grenadines }\end{array}$ & 0 & 10,932 \\
\hline 15 & Mexico & 286 & 5958 & 159 & $\begin{array}{c}\text { Saint Kitts and } \\
\text { Nevis }\end{array}$ & 0 & 13,248 \\
\hline 16 & Canada $\int$ & 234 & 88,515 & 158 & Seychelles & 0 & \\
\hline 17 & Switzerland $\int$ & 227 & 81,825 & 157 & Burundi & 0.08 & 563 \\
\hline 18 & Panama & 227 & 40,384 & 156 & Myanmar & 0.1 & 1770 \\
\hline 19 & Armenia & 205 & 47,718 & 155 & Taiwan & 0.3 & 3319 \\
\hline 20 & $\begin{array}{c}\text { North } \\
\text { Macedonia }\end{array}$ & 192 & 38,771 & 154 & Mozambique & 0.3 & 1360 \\
\hline
\end{tabular}

* Numbers per million population, USA-United States of America, UK-United Kingdom, VCT-Saint Vincent and the Grenadines. Bold letters with mark " " mean no recent national BCG vaccination program for all. 
Histograms of morbidities and mortalities were drawn as normal density plots (Figure 1). Although the histograms of morbidity and mortality were skewed to the right, they followed a normal distribution by transformation with the common logarithm $(\log 10)$.
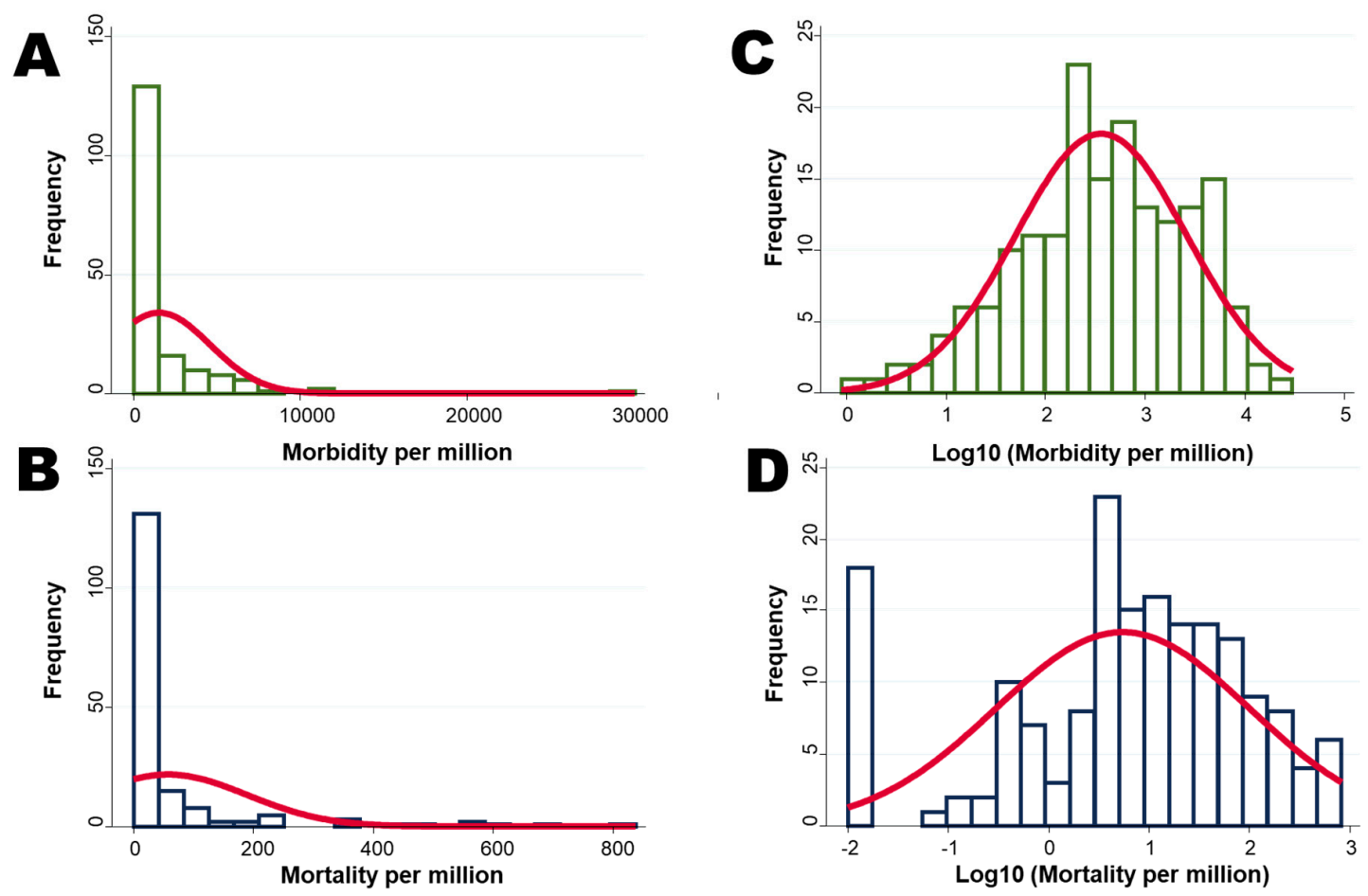

Figure 1. Histograms of morbidities and mortalities drawn as a normal density plot. (A) Morbidity per million; (B) mortality per million; (C) $\log 10$ transformed morbidity; and (D) $\log 10$ transformed mortality.

\subsection{Associations between Morbidity, Mortality and PCR-Tests per Million Population}

First, associations represented by rho and VIF between morbidity $(n=173)$, mortality $(n=173)$ and PCR-tests $(n=155)$ are shown (Figure 2A). These three variables were predicted to have very strong and positive associations with each other. However, VIFs were less than 2 among these three factors. Multicollinearity is considered to be present when the VIF is higher than 5 to 10 [24]. Thus, any variable with a VIF $<5.0$ was considered for inclusion in multiple linear regression analyses. Considering the number of PCR-tests per million population may exhibit associations with morbidity, adjustment was performed for the PCR-test number in every analysis when screening for the risk factors of COVID-19 morbidity per million population (Figure 2B). Considering morbidities and the number of PCR-tests per million population may exhibit associations with mortality, adjustment was performed for the morbidity and PCR-test number in every analysis when screening for the risk factors of COVID-19 mortality per million population (Figure 2C). 


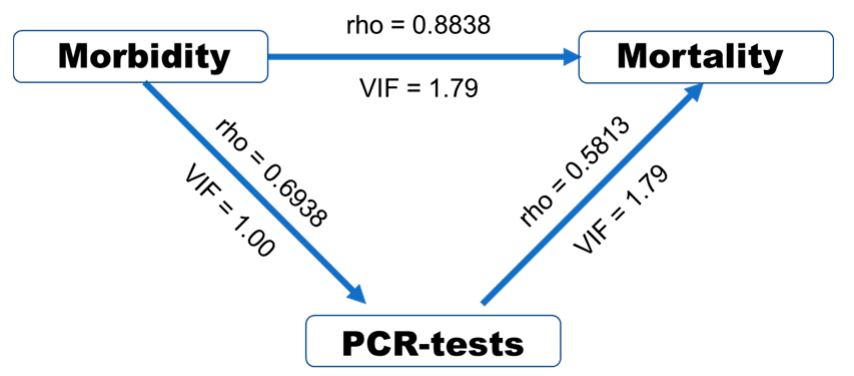

(A)

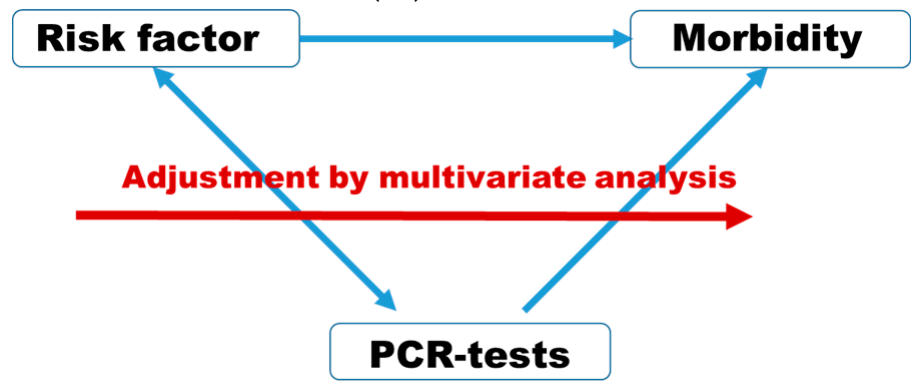

(B)

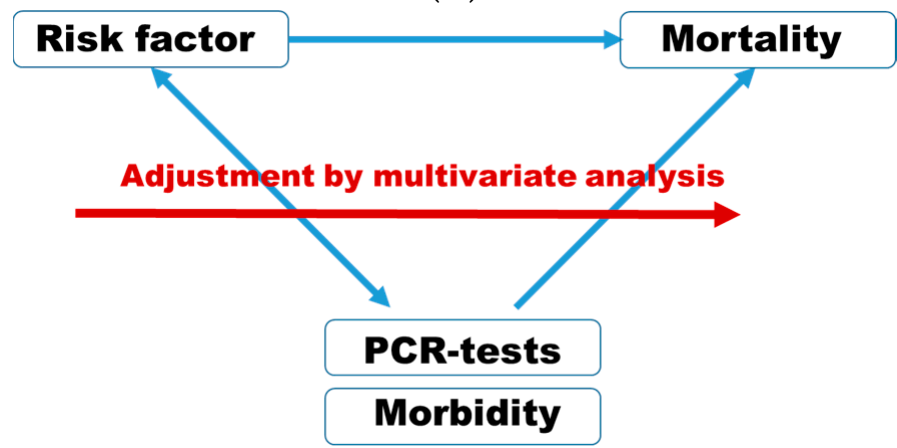

(C)

Figure 2. (A) Associations between morbidity, mortality and PCR-tests. Either Pearson's correlation coefficient or Spearman's rank correlation was applied to calculate rho; (B) associations between morbidity and risk factors were adjusted for PCR-tests per million population ( $\log 10)$; (C) associations between mortality and risk factors were adjusted for morbidity $(\log 10)$ and PCR-tests $(\log 10)$ per million population.

Since fewer PCR-tests may underestimate morbidity and mortality, the association between mortality as the outcome and morbidity as the exposure was adjusted for number of PCR-tests performed (Table 3). In this multiple regression analysis, higher morbidity was associated with higher mortality, whereas more PCR-tests were associated with lower mortality.

Table 3. Association between mortality as the outcome and morbidity as the exposure, adjusted for number of PCR-tests performed.

\begin{tabular}{cccccc}
\hline Variable & Coef. & Std. Err. & $p$-Value & $\mathbf{9 5 \%}$ CI & Adjusted R $^{\mathbf{2}}$ \\
\hline $\begin{array}{c}\text { Morbidity per million } \\
\text { population (log10) }\end{array}$ & 1.395 & 0.083 & $<0.001$ & 1.232 to 1.558 & 0.7067 \\
$\begin{array}{c}\text { PCR-tests per million } \\
\text { population (log10) }\end{array}$ & -0.241 & 0.086 & 0.005 & $\begin{array}{c}-0.416 \text { to } \\
-0.075\end{array}$ & \\
\hline
\end{tabular}

Coef.-Coefficient; Std. Err.-Standard Error; 95\% CI-95\% confidence interval. 
Evaluation of the association between PCR-test positivity and mortality, shown as a scatter plot, indicated a very strong association between them (rho $=0.54$ ) (Figure 3). Countries with higher PCR-positivity rates tended to have higher mortality rates. PCR-test positivity rates of countries where no deaths due to COVID-19 were observed were less than 3.5\%. Minimum positivity and no deaths were observed in Vietnam.

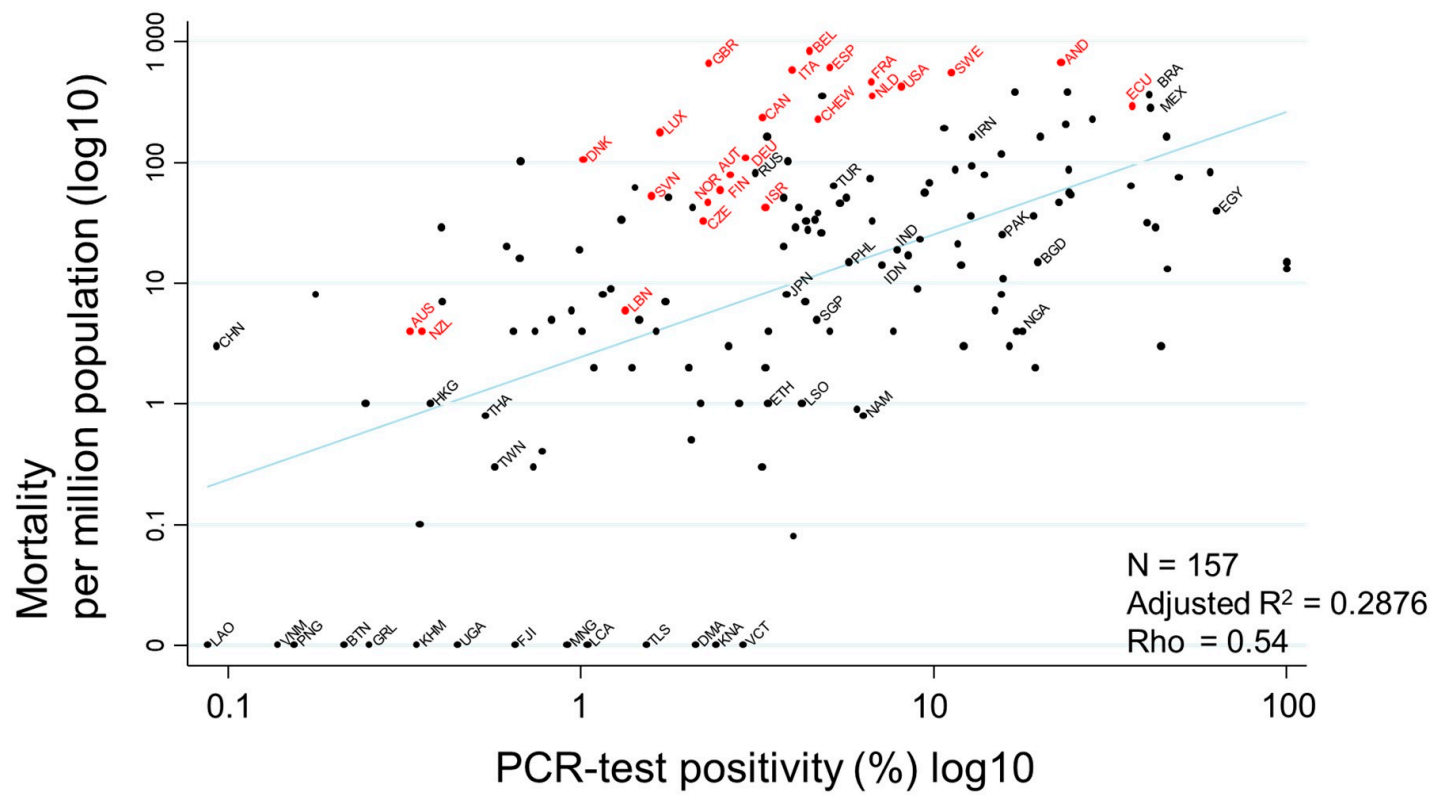

Figure 3. Scatter plot showing the association between PCR-test positivity and mortality. Mortality per million population and PCR-test positivity rates (\%) on 17 July 2020 were transformed to the common logarithm $(\log 10)$ in the graph. Since the variable of 'PCR-test positivity $(\log 10)$ ' showed a normal distribution, Pearson's correlation coefficient was applied to calculate rho, to quantify the strength of the association. Countries that never had or stopped a national BCG vaccine program are indicated in red, while countries with current national BCG vaccine programs are indicated in black. Selected country names are shown using three-letter country codes.

\subsection{Screening Factors Associated with Morbidity}

Among the 59 covariates, plus BCG vaccine coverage and PCR-testing rate, i.e., a total of 61 factors, 'urban population' and 'insufficient physical activity' were significantly $(p<0.001)$ associated with morbidity after adjustment for PCR-test rate (Table 4). Next, these two significant factors were used in a multi-linear regression model to eliminate confounding (Table 5). As a result, 'urban population' $(p=0.02)$ and 'insufficient physical activity' $(p=0.01)$ remained significant factors associated with COVID-19 morbidity, even after adjustment for PCR-tests. The adjusted $\mathrm{R}^{2}$ was 0.5037 . 
Table 4. Associations between COVID-19 morbidity and mortality per million population and world data for each country.

\begin{tabular}{|c|c|c|c|c|c|}
\hline Variable & $N * 3$ & Median, IQR & $\begin{array}{l}\text { Min (Country) } \\
\text { Max (Country) }\end{array}$ & $\begin{array}{l}\text { Morbidity }{ }^{* 1} \\
\text { Adjusted } \mathrm{R}^{2}\end{array}$ & $\begin{array}{l}\text { Mortality *2 } \\
\text { Adjusted } \mathbf{R}^{2}\end{array}$ \\
\hline Population, $n$ & 173 & $\begin{array}{c}1.02 \times 10^{7} \\
3.5 \times 10^{6}-3.3 \times 10^{7}\end{array}$ & $\begin{array}{c}3.9 \times 10^{5}(\text { Monaco }) \\
1.4 \times 10^{9}(\text { China })\end{array}$ & 0.3732 & 0.7120 \\
\hline Yearly change (\%) & 173 & $\begin{array}{c}1.11 \\
0.35-1.96\end{array}$ & $\begin{array}{l}-1.35 \text { (Lithuania) } \\
3.84 \text { (Niger) }\end{array}$ & 0.3822 & 0.7172 \\
\hline Net change, $n$ & 173 & $\begin{array}{c}89,516 \\
8516-447,563\end{array}$ & $\begin{array}{l}-383,840 \text { (Japan) } \\
1.40 \times 10^{7} \text { (India) }\end{array}$ & 0.3713 & 0.7073 \\
\hline Population density, $n / \mathrm{km}^{2}$ & 173 & $\begin{array}{c}83 \\
34-167\end{array}$ & $\begin{array}{c}0 \text { (Greenland) } \\
\text { 26,337 (Monaco) }\end{array}$ & 0.3723 & 0.7048 \\
\hline Land area, $\mathrm{km}^{2}$ & 173 & $\begin{array}{c}183,630 \\
35,410-581,795\end{array}$ & $\begin{array}{c}1 \text { (Monaco) } \\
1.6 \times 10^{7} \text { (Russia) }\end{array}$ & 0.3726 & 0.7079 \\
\hline Migrants, $n$ (net) & 168 & $\begin{array}{c}-1590 \\
-16,026-14,440.5\end{array}$ & $\begin{array}{c}-653,249 \text { (Venezuela) } \\
954,806 \text { (USA) }\end{array}$ & 0.3885 & 0.7460 \\
\hline Fertility rate, $n$ & 168 & $\begin{array}{c}2.27 \\
1.71-3.65\end{array}$ & $\begin{array}{l}1.11 \text { (Korea) } \\
6.95 \text { (Niger) }\end{array}$ & 0.3784 & 0.7516 \\
\hline Urban population (\%) & 168 & $\begin{array}{c}60 \\
43-78\end{array}$ & $\begin{array}{c}13 \text { (Papua New Guinea) } \\
98 \text { (Belgium) }\end{array}$ & $0.4246^{*}$ & 0.7243 \\
\hline World share (\%) & 173 & $\begin{array}{c}0.1 \\
0.05-0.4\end{array}$ & $\begin{array}{c}0 \text { (Saint Lucia, etc.) } \\
18.5 \text { (China) }\end{array}$ & 0.3732 & 0.7120 \\
\hline \multicolumn{6}{|c|}{ 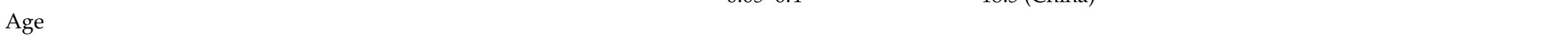 } \\
\hline Median age, years & 168 & $\begin{array}{c}30 \\
21.5-39\end{array}$ & $\begin{array}{l}15 \text { (Niger) } \\
48 \text { (Japan) }\end{array}$ & 0.3787 & $0.7811 *$ \\
\hline 0 to 14 years of age $(\%)$ & 165 & $\begin{array}{c}26.8 \\
17.6-37.3\end{array}$ & $\begin{array}{c}12.3 \text { (Niger) } \\
49.8 \text { (Singapore) }\end{array}$ & 0.3789 & 0.7574 \\
\hline$\geq 60$ years of age $(\%)$ & 165 & $\begin{array}{c}9.72 \\
5.30-20.48\end{array}$ & $\begin{array}{c}2.80 \text { (UAE) } \\
34.01 \text { (Japan) }\end{array}$ & 0.3802 & $0.7986 *$ \\
\hline$\geq 70$ years of age $(\%)$ & 162 & $\begin{array}{c}3.41 \\
2.03-9.17\end{array}$ & $\begin{array}{c}0.53 \text { (UAE) } \\
18.49 \text { (Japan) }\end{array}$ & 0.3818 & 0.8027 * \\
\hline \multicolumn{6}{|l|}{ Economy } \\
\hline GDP, million US dollars & 170 & $\begin{array}{c}40,729 \\
11,135-223,780\end{array}$ & $\begin{array}{c}393 \text { (Sao Tome) } \\
1.90 \times 10^{7} \text { (USA) }\end{array}$ & 0.3701 & 0.7095 \\
\hline GDP per capita, US dollars & 170 & $\begin{array}{c}51.4 \\
1534-15,347\end{array}$ & $\begin{array}{c}104 \text { (Somalia) } \\
165,421 \text { (Monaco) }\end{array}$ & 0.3722 & 0.7051 \\
\hline Total unemployment rate (\%) & 164 & $\begin{array}{c}5.85 \\
3.75-9.40\end{array}$ & $\begin{array}{c}0.1 \text { (Qatar) } \\
28.2 \text { (Lesotho) }\end{array}$ & 0.3933 & 0.7436 \\
\hline
\end{tabular}


Table 4. Cont.

\begin{tabular}{|c|c|c|c|c|c|}
\hline Variable & $N * 3$ & Median, IQR & $\begin{array}{l}\text { Min (Country) } \\
\text { Max (Country) }\end{array}$ & $\begin{array}{l}\text { Morbidity }{ }^{* 1} \\
\text { Adjusted } R^{2}\end{array}$ & $\begin{array}{l}\text { Mortality *2 } \\
\text { Adjusted } R^{2}\end{array}$ \\
\hline Male unemployment rate (\%) & 164 & $\begin{array}{c}5.5 \\
3-8.5\end{array}$ & $\begin{array}{c}0 \text { (Qatar) } \\
26 \text { (Eswatini) }\end{array}$ & 0.3905 & 0.7433 \\
\hline Female unemployment rate (\%) & 164 & $\begin{array}{c}7 \\
4-12\end{array}$ & $\begin{array}{l}0 \text { (Niger) } \\
38 \text { (Syria) }\end{array}$ & 0.4078 & 0.7435 \\
\hline Total labor force participation rate (\%) & 164 & $\begin{array}{c}62 \\
55-68\end{array}$ & $\begin{array}{l}38 \text { (Yemen) } \\
87 \text { (Qatar) }\end{array}$ & 0.3939 & 0.7597 \\
\hline Male labor force participation rate (\%) & 164 & $\begin{array}{c}73 \\
66.5-79\end{array}$ & $\begin{array}{l}45 \text { (Moldova) } \\
95 \text { (Qatar) }\end{array}$ & 0.3809 & 0.7602 \\
\hline Female labor force participation rate (\%) & 164 & $\begin{array}{c}53.5 \\
45-60.5\end{array}$ & $\begin{array}{c}6 \text { (Yemen) } \\
84 \text { (Rwanda) }\end{array}$ & 0.4216 & 0.7479 \\
\hline $\begin{array}{l}\text { National BCG vaccine program } \\
\text { Annual incidence of tuberculosis, } \\
n / 100,000\end{array}$ & 164 & $\begin{array}{c}57 \\
17-176\end{array}$ & $\begin{array}{c}2 \text { (UAE) } \\
834 \text { (South Africa) }\end{array}$ & 0.3693 & 0.7053 \\
\hline Recent BCG vaccine coverage (\%) & 173 & $\begin{array}{c}93 \\
81-98\end{array}$ & $\begin{array}{c}0 \text { (Italy, etc.) } \\
99 \text { (Japan, etc.) }\end{array}$ & 0.3814 & $0.7415 *$ \\
\hline \multicolumn{6}{|l|}{$\begin{array}{l}\text { Global health observatory } \\
\text { Health policy }\end{array}$} \\
\hline International Health Regulations score & 170 & $\begin{array}{c}64 \\
48 \text { to } 82\end{array}$ & $\begin{array}{l}17 \text { (Central African } \\
\text { Republic) } \\
99 \text { (Canada, Russia) }\end{array}$ & 0.3817 & 0.7205 \\
\hline Universal health coverage index & 166 & $\begin{array}{c}0.41 \\
0.36 \text { to } 0.47\end{array}$ & $\begin{array}{l}0.17 \text { (Saint Lucia) } \\
0.70 \text { (Peru) }\end{array}$ & 0.3812 & $0.7644 *$ \\
\hline $\begin{array}{l}\text { Total expenditure on health as a } \\
\text { percentage of gross domestic product }\end{array}$ & 169 & $\begin{array}{c}6.38 \\
4.76-8.43\end{array}$ & $\begin{array}{l}1.48 \text { (Timor-Leste) } \\
17.14 \text { (USA) }\end{array}$ & 0.3977 & 0.7283 \\
\hline $\begin{array}{l}\text { Population with household expenditures } \\
\text { on health greater than } 10 \% \text { of total } \\
\text { household expenditure/income (\%) } \\
\text { Medical personnel }\end{array}$ & 146 & $\begin{array}{c}6.56 \\
3.13-12.76\end{array}$ & $\begin{array}{c}0.20 \text { (Gambia) } \\
54.2 \text { (Sierra Leone) }\end{array}$ & 0.3956 & 0.7906 \\
\hline Hospital beds, $n / 10,000$ population & 164 & $\begin{array}{c}21 \\
11-40\end{array}$ & $\begin{array}{c}1 \text { (Mali) } \\
134 \text { (Japan) }\end{array}$ & 0.3718 & 0.7409 \\
\hline Medical doctors, $n / \mathbf{1 0 , 0 0 0}$ population & 169 & $\begin{array}{c}15.7 \\
3.3-29.8\end{array}$ & $\begin{array}{l}0.1 \text { (Tanzania) } \\
84.2 \text { (Cuba) }\end{array}$ & 0.3800 & $0.7351 *$ \\
\hline $\begin{array}{l}\text { Nursing and midwifery personnel, } \\
n / 10,000 \text { population }\end{array}$ & 169 & $\begin{array}{c}26.6 \\
9.4-64.4\end{array}$ & $\begin{array}{l}0.06 \text { (Cameroon) } \\
201.6 \text { (Monaco) }\end{array}$ & 0.3823 & 0.7203 \\
\hline
\end{tabular}


Table 4. Cont.

\begin{tabular}{|c|c|c|c|c|c|}
\hline Variable & $N * 3$ & Median, IQR & $\begin{array}{l}\text { Min (Country) } \\
\text { Max (Country) }\end{array}$ & $\begin{array}{l}\text { Morbidity }{ }^{* 1} \\
\text { Adjusted } \mathrm{R}^{2}\end{array}$ & $\begin{array}{l}\text { Mortality *2 } \\
\text { Adjusted } R^{2}\end{array}$ \\
\hline $\begin{array}{l}\text { Licensed qualified anesthesiologists } \\
\text { actively working, } n \\
\text { Health biomarkers }\end{array}$ & 141 & $\begin{array}{c}250 \\
18-1511\end{array}$ & $\begin{array}{c}0 \text { (Congo) } \\
194,634 \text { (China) }\end{array}$ & 0.3904 & 0.6924 \\
\hline $\begin{array}{l}\text { High blood pressure (SBP > } 140 \text { OR DBP } \\
>90) \text { (crude estimate) }(\%)\end{array}$ & 167 & $\begin{array}{c}23 \\
20-25\end{array}$ & $\begin{array}{c}13 \text { (Peru) } \\
41 \text { (Croatia) }\end{array}$ & 0.4091 & 0.7199 \\
\hline $\begin{array}{l}\text { Elevated fasting blood glucose } \\
(>7.0 \mathrm{mmol} / \mathrm{L} \text { or on medication) (crude } \\
\text { estimate) }(\%)\end{array}$ & 167 & $\begin{array}{c}8.1 \\
5.9-9.7\end{array}$ & $\begin{array}{l}2.6 \text { (Burundi) } \\
16.6 \text { (Fiji) }\end{array}$ & 0.4069 & 0.7162 \\
\hline $\begin{array}{l}\text { Elevated total cholesterol }(\geq 5.0 \mathrm{mmol} / \mathrm{L} \\
\text { or } 193 \mathrm{mg} / \mathrm{dL} \text { ) } \\
\text { (crude estimate) (\%) } \\
\text { BMI }\end{array}$ & 167 & $\begin{array}{c}37.6 \\
25.2-52.5\end{array}$ & $\begin{array}{l}14.8 \text { (Niger) } \\
69.7 \text { (Denmark) }\end{array}$ & 0.4070 & 0.7401 * \\
\hline Mean BMI, $\mathrm{kg} / \mathrm{m}^{2}$ & 167 & $\begin{array}{c}26.2 \\
23.4-27.2\end{array}$ & $\begin{array}{c}20.5 \text { (Ethiopia) } \\
30.0 \text { (Saint Lucia) }\end{array}$ & 0.4233 & 0.7102 \\
\hline $\mathrm{BMI} \geq 30 \mathrm{~kg} / \mathrm{m}^{2}(\%)$ & 167 & $\begin{array}{c}19.9 \\
7.5-25.7\end{array}$ & $\begin{array}{l}2.1 \text { (Vietnam) } \\
37.3 \text { (USA) }\end{array}$ & 0.4393 & 0.7135 \\
\hline $\mathrm{BMI} \geq 25 \mathrm{~kg} / \mathrm{m}^{2}(\%)$ & 167 & $\begin{array}{c}53.5 \\
27.8-62.2\end{array}$ & $\begin{array}{l}17.9 \text { (Timor-Leste) } \\
72.1 \text { (Kuwait) }\end{array}$ & 0.4454 & 0.7204 \\
\hline $\begin{array}{l}\text { Alcohol drinking, total consumption per } \\
\text { capita among persons aged } \geq 15 \text { years, } \\
\text { liters of pure alcohol over a calendar year }\end{array}$ & 168 & $\begin{array}{c}6.4 \\
2.6-9.8\end{array}$ & $\begin{array}{r}0 \text { (Bangladesh) } \\
15.2 \text { (Moldova) }\end{array}$ & 0.3834 & 0.7191 \\
\hline $\begin{array}{l}\text { Prevalence of smoking any tobacco } \\
\text { product among males aged } \geq 15 \text { years }(\%)\end{array}$ & 119 & $\begin{array}{c}32 \\
23-44\end{array}$ & $\begin{array}{c}9 \text { (Ethiopia) } \\
76 \text { (Indonesia) }\end{array}$ & 0.4410 & 0.8006 \\
\hline $\begin{array}{l}\text { Prevalence of smoking any tobacco } \\
\text { product among females aged } \geq 15 \text { years } \\
(\%)\end{array}$ & 119 & $\begin{array}{c}8 \\
3-19\end{array}$ & $\begin{array}{c}0 \text { (Niger) } \\
40 \text { (Serbia) }\end{array}$ & 0.3932 & 0.8192 \\
\hline $\begin{array}{l}\text { Prevalence of insufficient physical } \\
\text { activity among adults aged } \geq 15 \text { years } \\
\text { (crude estimate) }(\%)\end{array}$ & 143 & $\begin{array}{c}28.7 \\
19.0-36.2\end{array}$ & $\begin{array}{l}5.0 \text { (Uganda) } \\
65.3 \text { (Kuwait) }\end{array}$ & 0.4984 * & 0.7270 \\
\hline $\begin{array}{l}\text { Estimated population-based prevalence } \\
\text { of depression }(\%)\end{array}$ & 166 & $\begin{array}{c}4.4 \\
4.0-5.0\end{array}$ & $\begin{array}{c}3.0 \text { (Papua New Guinea) } \\
6.3 \text { (Ukraine) }\end{array}$ & 0.4062 & 0.7486 \\
\hline
\end{tabular}


Table 4. Cont.

\begin{tabular}{|c|c|c|c|c|c|}
\hline Variable & $N * 3$ & Median, IQR & $\begin{array}{l}\text { Min (Country) } \\
\text { Max (Country) }\end{array}$ & $\begin{array}{l}\text { Morbidity }{ }^{* 1} \\
\text { Adjusted } R^{2}\end{array}$ & $\begin{array}{l}\text { Mortality *2 } \\
\text { Adjusted } \mathbf{R}^{2}\end{array}$ \\
\hline Mortality according to age group & & & & & \\
\hline $\begin{array}{l}\text { Neonatal mortality rate, } n \text { per } 1000 \text { live } \\
\text { births }\end{array}$ & 170 & $\begin{array}{c}9.6 \\
3.5-21.0\end{array}$ & $\begin{array}{c}0.9 \text { (Japan) } \\
42.0 \text { (Pakistan) }\end{array}$ & 0.3811 & 0.7234 \\
\hline $\begin{array}{l}\text { Infantile mortality rate, } n \text { per } 1000 \text { live } \\
\text { births }\end{array}$ & 170 & $\begin{array}{c}14.0 \\
5.9-34.9\end{array}$ & $\begin{array}{l}1.4 \text { (Finland) } \\
84.5 \text { (Central African } \\
\text { Republic) }\end{array}$ & 0.3810 & 0.7507 \\
\hline $\begin{array}{l}\text { Under-five mortality rate, probability of } \\
\text { dying by age } 5 / 1000 \text { live births }\end{array}$ & 170 & $\begin{array}{c}14.4 \\
7.0-44.2\end{array}$ & $\begin{array}{c}1.7 \text { (Finland) } \\
121.5 \text { (Somalia) }\end{array}$ & 0.3813 & 0.7145 \\
\hline $\begin{array}{l}\text { Mortality rate for } 5-14 \text {-year-olds, } n / 1000 \\
\text { children aged 5-14 years }\end{array}$ & 168 & $\begin{array}{c}2.8 \\
1.5-8.6\end{array}$ & $\begin{array}{l}0.4 \text { (Luxembourg) } \\
37.3 \text { (Niger) }\end{array}$ & 0.3781 & 0.7117 \\
\hline $\begin{array}{l}\text { Adult mortality rate, probability of dying } \\
\text { between } 15 \text { and } 60 \text { years of age/ } 1000 \\
\text { population }\end{array}$ & 167 & $\begin{array}{c}150 \\
96-224\end{array}$ & $\begin{array}{l}49 \text { (Switzerland) } \\
484 \text { (Lesotho) }\end{array}$ & 0.3812 & 0.7377 \\
\hline $\begin{array}{l}\text { Probability of dying between age } 30 \text { and } \\
\text { exact age } 70 \text { from cardiovascular disease, } \\
\text { cancer, diabetes or chronic respiratory } \\
\text { disease } \\
\text { Life expectancy at birth, years }\end{array}$ & 166 & $\begin{array}{c}18.4 \\
14.7-22.6\end{array}$ & $\begin{array}{c}7.8 \text { (Korea) } \\
30.6 \text { (Yemen) }\end{array}$ & 0.3886 & 0.7061 \\
\hline At birth & 166 & $\begin{array}{c}73.4 \\
65.3-81.5\end{array}$ & $\begin{array}{l}52.9 \text { (Lesotho) } \\
84.2 \text { (Japan) }\end{array}$ & 0.3806 & 0.7600 \\
\hline At age 60 years & 166 & $\begin{array}{c}19.6 \\
17.2-22.1\end{array}$ & $\begin{array}{l}13.4 \text { (Sierra Leone) } \\
26.4 \text { (Japan) }\end{array}$ & 0.3838 & 0.7630 \\
\hline Healthy life expectancy (HALE), years & & & & & \\
\hline At birth & 166 & $\begin{array}{c}65.3 \\
57.5-68.1\end{array}$ & $\begin{array}{l}44.9 \text { (Central African } \\
\text { Republic) } \\
76.2 \text { (Singapore) }\end{array}$ & 0.3795 & 0.7599 \\
\hline
\end{tabular}


Table 4. Cont.

\begin{tabular}{|c|c|c|c|c|c|}
\hline Variable & $N * 3$ & Median, IQR & $\begin{array}{l}\text { Min (Country) } \\
\text { Max (Country) }\end{array}$ & $\begin{array}{l}\text { Morbidity }{ }^{* 1} \\
\text { Adjusted } \mathrm{R}^{2}\end{array}$ & $\begin{array}{l}\text { Mortality *2 } \\
\text { Adjusted R }\end{array}$ \\
\hline At age 60 years & 166 & $\begin{array}{c}14.8 \\
13.0-17.1\end{array}$ & $\begin{array}{l}10.3 \text { (Sierra Leone) } \\
21.0 \text { (Singapore) }\end{array}$ & 0.3825 & $0.7652 *$ \\
\hline \multicolumn{6}{|l|}{ Disease-specific mortality } \\
\hline Chronic obstructive pulmonary disease & 166 & $6.13 .9-8.3$ & $\begin{array}{c}0.6 \text { (Qatar) } \\
36.8 \text { (India) }\end{array}$ & 0.3975 & 0.7436 \\
\hline Ischemic heart disease & 166 & $\begin{array}{c}21.5 \\
13.4-35.2\end{array}$ & $\begin{array}{l}4.9 \text { (Brunei Darussalam) } \\
106.9 \text { (Georgia) }\end{array}$ & 0.3789 & 0.7431 \\
\hline Lower respiratory infections & 166 & $\begin{array}{c}8.2 \\
3.7-31.6\end{array}$ & $\begin{array}{l}0.22 \text { (Finland) } \\
130.3(\text { Chad })\end{array}$ & 0.3791 & 0.7455 \\
\hline Stroke & 166 & $\begin{array}{c}10.2 \\
5.6-16.6\end{array}$ & $\begin{array}{c}1.4 \text { (Qatar) } \\
49.3 \text { (Georgia) }\end{array}$ & 0.3963 & 0.7726 \\
\hline Tracheal, bronchial, lung cancers & 166 & $\begin{array}{c}1.8 \\
0.8-4.2\end{array}$ & $\begin{array}{l}0.2 \text { (Niger) } \\
20.5 \text { (China) }\end{array}$ & 0.3971 & 0.7541 \\
\hline $\begin{array}{l}\text { Air pollution } \\
\text { Ambient and household air pollution } \\
\text { attributable death rate } / 100,000 \\
\text { population }\end{array}$ & 166 & $\begin{array}{c}65.9 \\
38.5-97.8\end{array}$ & $\begin{array}{c}8.5 \text { (Georgia) } \\
184 \text { (Brunei Darussalam) }\end{array}$ & 0.3861 & 0.7427 \\
\hline $\begin{array}{l}\text { Concentrations of fine particulate matter } \\
\left(\mathrm{PM}_{2.5}\right)\end{array}$ & 170 & $\begin{array}{c}21.1 \\
14.6-34.7\end{array}$ & $\begin{array}{l}5.7 \text { (New Zealand) } \\
94.3 \text { (Nepal) }\end{array}$ & 0.3940 & 0.7210 \\
\hline $\begin{array}{l}\text { Coverage rate with the first dose of a } \\
\text { measles-containing-vaccine (MCV1) } \\
\text { among one-year-olds (\%) }\end{array}$ & 169 & $\begin{array}{c}93 \\
84-97\end{array}$ & $\begin{array}{l}30 \text { (Equatorial Guinea) } \\
99 \text { (Mongolia and } 23 \text { other } \\
\text { countries) }\end{array}$ & 0.3851 & 0.7095 \\
\hline
\end{tabular}

IQR—interquartile range; GDP—gross domestic product; BMI—body mass index—weight $(\mathrm{kg}) /$ height $(\mathrm{m})^{2} ; * 1$ —adjusted for PCR tests per million population; *2 —adjusted for PCR tests and COVID-19 morbidity per million population; ${ }^{*}{ }^{3}$-number of countries the data were able to abstract, ${ }^{*}: p<0.001$. Bold letters mean statistically significant: $p<0.001$. 
Table 5. Factors associated with morbidity adjusted for PCR-test rates.

\begin{tabular}{cccccc}
\hline Variable & Coef. & Std. Err. & $p$-Value & $\mathbf{9 5 \%}$ CI & Adjusted R \\
\hline PCR-tests per million & 0.574 & 0.101 & $<0.001$ & 0.374 to 0.774 & \\
$\begin{array}{c}\text { population (log10) } \\
\text { Urban population (\%) }\end{array}$ & 0.764 & 0.329 & 0.02 & 0.113 to 1.416 & 0.5037 \\
$\begin{array}{c}\text { Insufficient physical } \\
\text { activity (\%) }\end{array}$ & 0.015 & 0.006 & 0.01 & 0.004 to 0.026 & \\
\hline
\end{tabular}

Coef.-Coefficient; Std. Err.-Standard Error; 95\% CI—-95\% confidence interval.

The association between 'urban population' and morbidity, demonstrated below as a scatter plot, showed a very strong association $(\mathrm{rho}=0.55)$ (Figure 4$)$.

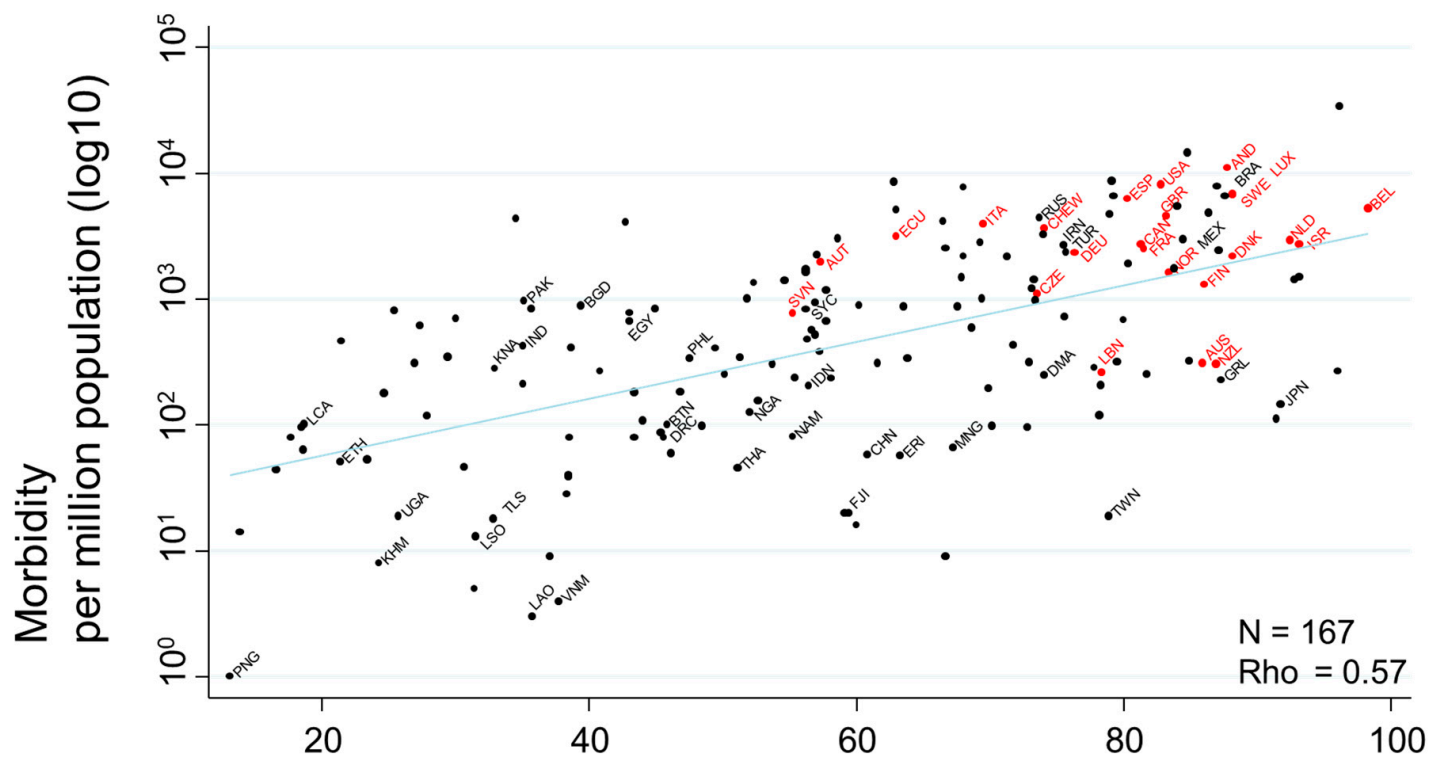

\section{Urban population (\%)}

Figure 4. Scatter plot showing the association between urban population and COVID-19 morbidity rates. COVID-19-related morbidity rates per million population on 17 July 2020 were transformed to the common logarithm $(\log 10)$ in the graph. Since the variable of 'urban population' showed a non-normal distribution, Spearman's rank correlation was applied to calculate rho, to quantify the strength of the association. Countries that had never had or that had stopped a national program of BCG vaccination are indicated in red, while countries that currently follow a national BCG vaccine program are indicated in black. Selected country names are shown using three-letter country codes.

The association between 'insufficient physical activity' and morbidity, demonstrated below as a scatter plot, also showed a very strong association (rho $=0.52)$ (Figure 5).

COVID-19-related morbidity rates per million population on July 17 th were transformed to the common logarithm $(\log 10)$ in the graph. Countries that had never had or that had stopped a national program of BCG vaccination are indicated in red, while countries that currently follow a national BCG vaccine program are indicated in black. Selected country's name was shown using three-letter country codes. 


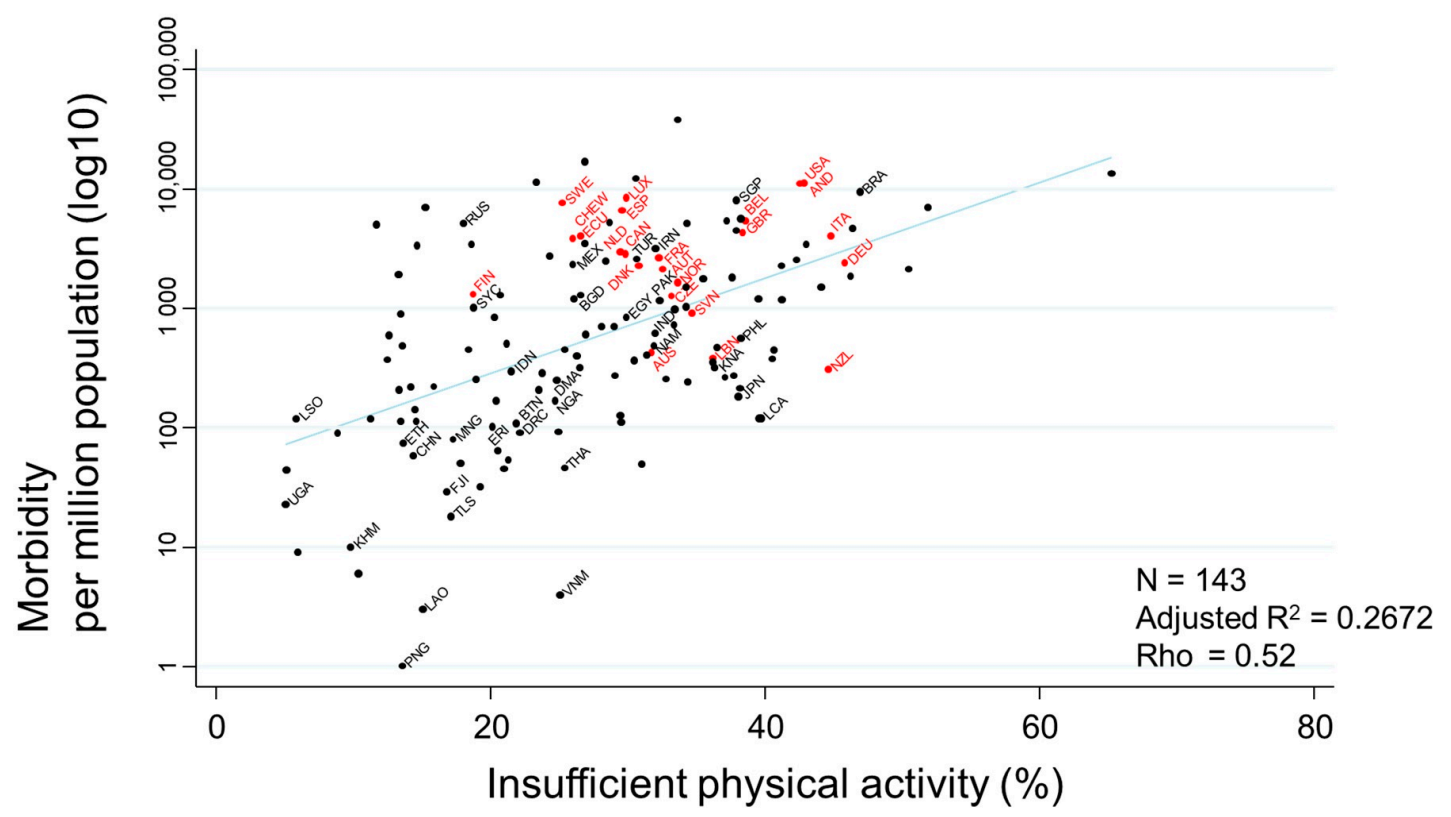

Figure 5. Scatter plot showing the association between insufficient physical activity and COVID-19 morbidity rates.

\subsection{Screening Factors Associated with Mortality}

Among the 58 covariates evaluated, plus BCG vaccine coverage, adjusted for morbidity and PCR-tests, age-related factors, i.e., median age, $\geq 60$ years of age (\%) and $\geq 70$ years of age $(\%)$, were significantly $(p<0.001)$ associated with mortality (Table 4$)$. Since these three age-related factors had collinearity for mortality, ' $\geq 60$ years of age' was selected to maximize adjusted $R^{2}$ of the multi-linear regression models. Moreover, 'BCG vaccine coverage', 'Elevated total cholesterol levels' and 'Life expectancy at 60 years of age', were also significant $(p<0.001)$ factors associated with mortality. Next, these significant factors were used in a multi-linear regression model to eliminate confounding (Table 6). As a result, ' $\geq 60$ years of age' $(p<0.001)$ and 'BCG vaccine coverage' $(p=0.002)$ remained significant factors associated with COVID-19 mortality, even after adjustment for morbidity and PCR-tests. The adjusted $R^{2}$ was 0.8254 .

Table 6. Factors associated with mortality adjusted for morbidity and PCR-test rates.

\begin{tabular}{ccccc}
\hline Variable & Coef. & Std. Err. & $p$-Value & 95\% CI \\
\hline Morbidity per million population $(\log 10)$ & 1.342 & 0.067 & $<0.001$ & 1.210 to 1.475 \\
PCR-tests per million population $(\log 10)$ & -0.485 & 0.099 & $<0.001$ & -0.680 to -0.290 \\
Population $\geq$ 60 years of age $(\%)$ & 0.030 & 0.010 & 0.003 & 0.011 to 0.050 \\
BCG vaccine coverage & -0.004 & 0.002 & 0.006 & -0.007 to -0.001 \\
Universal health coverage & 1.473 & 0.549 & 0.008 & 0.387 to 2.560 \\
Medical doctors/10,000 population & 0.003 & 0.004 & 0.47 & -0.005 to 0.011 \\
Elevated total cholesterol & 0.002 & 0.006 & 0.76 & -0.010 to 0.014 \\
HALE at age 60 & -0.03 & 0.029 & 0.27 & -0.090 to 0.025 \\
\hline
\end{tabular}

HALE—-healthy life expectancy, Coef.-Coefficient; Std. Err.-Standard Error; 95\% CI—95\% confidence interval.

Evaluation of the association between 'median age' and mortality, demonstrated as a scatter plot, showed a very strong association between these two variables $($ rho $=0.54)$ (Figure 6$)$. Countries with a larger population $\geq 60$ years of age (\%) showed a tendency toward a higher mortality rate.

Finally, evaluation of the association between 'BCG vaccine coverage' and mortality, demonstrated as a scatter plot, indicated a moderately negative association $($ rho $=-0.29)$ (Figure 7$)$. Countries with higher BCG vaccine coverage showed a tendency toward lower mortality. Additionally, COVID-19 mortality rates did not have significant associations with BCG strain, e.g., Tokyo 172. Moreover, 
there were no significant associations between mortality and either the year of stopping or introducing a national BCG vaccine program (data not shown).

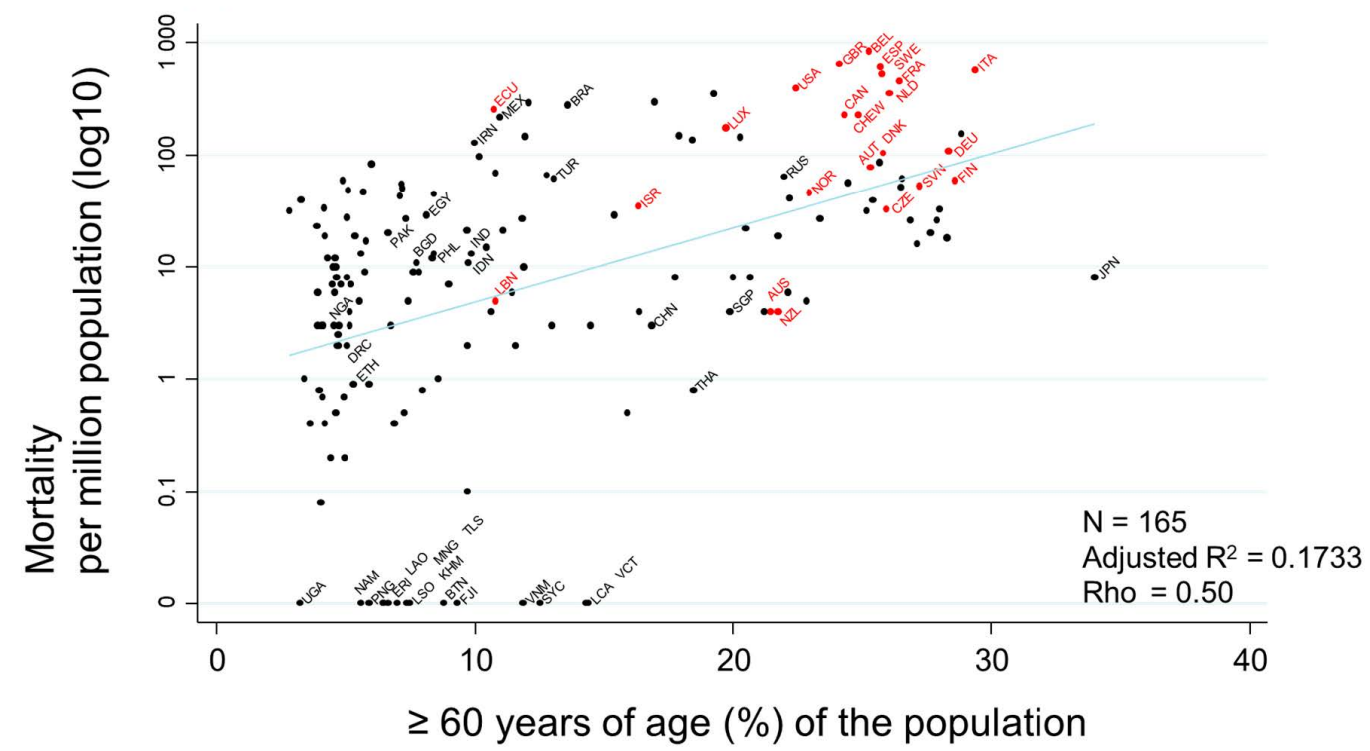

Figure 6. Scatter plot showing the association between $\geq 60$ years of age (\%) of the population and mortality rate. Mortalities per million population on 17 July 2020 transformed to the common logarithm $(\log 10)$ are presented in the graph. Since the variable of 'percentage of population $\geq 60$ years of age $(\%)^{\prime}$ showed a non-normal distribution, Spearman's rank correlation was applied to calculate rho, to quantify the strength of the association. Countries that had never had or that had stopped their national BCG vaccine program are indicated in red, while countries that currently follow a national BCG vaccine program are indicated in black. Selected country names are shown using three-letter country codes.

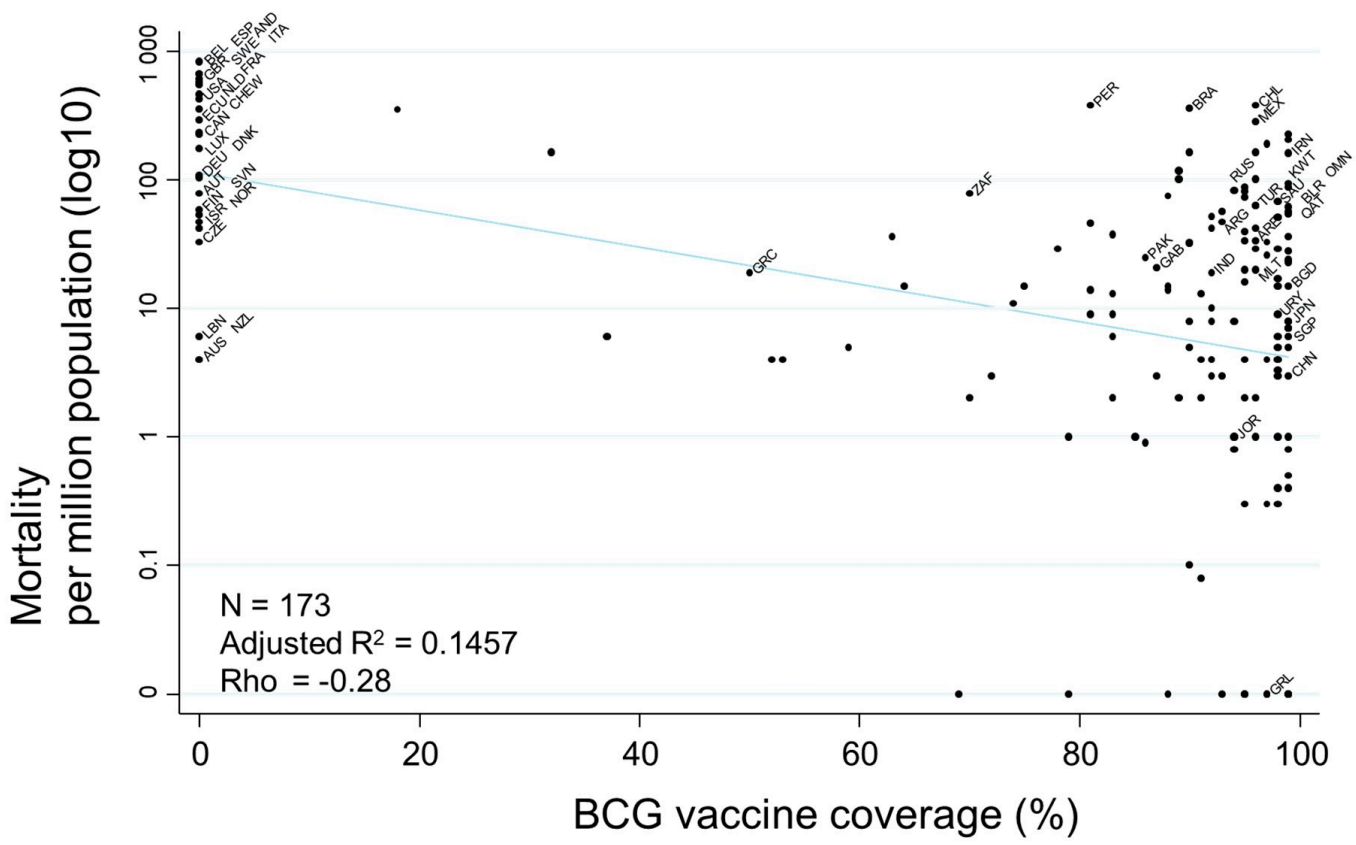

Figure 7. Scatter plot showing the association between COVID-19-related mortality and BCG vaccine coverage. Mortalities per million population on 17 July 2020 are transformed to the common logarithm $(\log 10)$ in the graph. Since the variable of 'BCG vaccine coverage' showed a non-normal distribution, Spearman's rank correlation was applied to calculate rho, to quantify the strength of the association. Selected country names are shown using three-letter country codes. 


\section{Discussion}

Among the variety of parameters abstracted from open resources, 'BCG vaccine coverage' had a significant association with COVID-19 mortality, even after adjusting for morbidity, PCR-tests, age, universal health coverage, numbers of medical doctors, elevated total cholesterol and healthy life expectancy. On the other hand, BCG vaccination was not associated with COVID-19 morbidity. The main results of this study are consistent with a very recent article demonstrating that every $10 \%$ increase in the BCG index was associated with a 10\% reduction in COVID-19 mortality [25]. Moreover, a retrospective cohort study suggested that BCG-vaccinated individuals were less likely to require hospital admission during the disease course [26]. In contrast to BCG, coverage of the measles vaccine, which is also considered to induce heterologous protection against infections through long-term boosting of innate immune responses [9], showed no association with the morbidity and mortality of COVID-19, which was also consistent with a very recent article showing a significant low risk of COVID-19 mortality in countries with higher BCG vaccine coverage, but not with measles vaccine coverage [27].

Moreover, SARS-CoV-2 is a single-stranded positive-sense RNA virus and the BCG vaccine has been shown in controlled trials to reduce the severity of infections by other viruses with such a structure [9]. For example, the BCG vaccine reduced yellow fever vaccine viremia by $71 \%$ in volunteers in the Netherlands [28]. However, some countries with a current national BCG vaccination policy have high mortality rates. Plausible reasons for this discrepancy may be: (1) low coverage of BCG vaccination in these countries (\% coverage-mortality per million population), e.g., Ireland $(18 \%-354)$; Portugal (32\%-165); and Greece (50\%-19): (2) late introduction of BCG vaccine program (year of introduction-mortality per million population), e.g., Iran, (1984-162): (3) oral delivery of the BCG vaccine, e.g., Brazil retained oral delivery of the vaccine until 1977: (4) UK administered the vaccine to older children (12 to 13 years of age) and (5) connection with endemic country by land, e.g., Mexico, Panama, Peru and Chile.

Higher morbidity, but fewer PCR-tests, were associated with higher mortality. Moreover, higher PCR-test positivity was associated with higher mortality, which was consistent with the report by Hisaka et al. [29]. Expanding application of PCR-tests not only to typical symptomatic cases, but also to mild or asymptomatic cases and to those who had close contact with patients, may decrease the PCR-test positivity rate. Thus, enhancing the capacity of PCR-testing may enable identification of cases, so that appropriate measures can be taken to prevent them spreading SARS-CoV-2 to others at home, at their work place or at events of mass gatherings.

In this study, the covariate of 'urban population' and 'insufficient physical inactivity' had a strong and positive association with morbidity, but not with mortality. People living in urban areas tend to have close contact with a greater number of people per day than those in rural areas, independent of age. A report on 4103 patients with COVID-19 in New York City found that obesity, which may strongly depend on the balance between physical activity and diet, was one of the clinical features leading to hospital admission [30]. On the other hand, older age was associated with higher mortality, which is consistent with previous articles [2-4]. From this study, the risk factors for morbidity seem to be different from those associated with mortality, suggesting that factors related to susceptibility may be different from those related to disease severity.

There are several limitations to this study. First, although we selected 61 covariates in this study, we did not evaluate range and timing of non-pharmaceutical interventions, e.g., school closures, workplace closures, cancellation of public events, restrictions on public gatherings, stay-at-home restrictions, restrictions on internal movement, international travel controls, etc., all of which would also have had significant effects on COVID-19-related morbidity and mortality. Therefore, the present study results are burdened with an extreme error. Second, the study design was ecological. Therefore, the outcome of this work should be considered highly limited, with a potential risk of high bias. Consequently, only the hypothesis that BCG vaccination mitigates COVID-19 mortality can be proposed here; cohort or case-control studies and randomized clinical trials, similar to the BCG-CORONA 
study [31], are required to test this hypothesis. Third, the COVID-19 pandemic is still ongoing, although we have confirmed the results using the latest data. However, the results may be different a few months from now. Fourth, it is clear that an extremely large number of covariates, i.e., 61, were selected for the limited number of 173 countries. This sample size could allow use of a maximum of 10 covariates in multiple regression analysis. Therefore, significant $(p<0.001)$ variables were at first screened after adjustment for PCR-tests and morbidity (Table 4). Then, multivariable linear regression using the screened variables were performed after adjustment for PCR-tests and morbidity (Table 5 for morbidity and Table 6 for mortality). Fifth, mortality in each country should be compared with excess deaths whether these two do not make a big difference. Sixth, the definition of COVID-19 cases may differ by country, e.g., including PCR confirmed, but asymptomatic cases and pneumonia cases with negative PCR-tests. Seventh, there were still residual confounders even after adjustment for PCR-tests.

\section{Conclusions}

Our results suggest the hypothesis that greater BCG vaccine coverage may reduce the risk of deaths due to COVID-19, which needs to be further studied by observational studies and confirmed by randomized clinical trials.

Supplementary Materials: The following are available online at http://www.mdpi.com/1660-4601/17/15/5589/s1, Table S1: Definitions or descriptions of all covariates.

Author Contributions: Conceptualization, M.U.; methodology, M.U., K.O., Y.H.; validation, T.A., M.U.; formal analysis, M.U., T.A.; resources, T.A.; data curation, T.A.; writing - original draft preparation, M.U.; writing-review and editing, K.O., Y.H., T.A.; visualization, M.U. All authors have read and agreed to the published version of the manuscript. These four authors contributed equally to this work.

Funding: This research received no external funding.

Acknowledgments: The authors thank the personnel who created the excellent open resources. We also thank Haruka Wada for data management at the Division of Molecular Epidemiology, Jikei University School of Medicine.

Conflicts of Interest: The authors declare no conflict of interest.

\section{References}

1. Murray, C.J.; Lopez, A.D.; Chin, B.; Feehan, D.; Hill, K.H. Estimation of potential global pandemic influenza mortality on the basis of vital registry data from the 1918-20 pandemic: A quantitative analysis. Lancet 2006, 368, 2211-2218. [CrossRef]

2. Price-Haywood, E.G.; Burton, J.; Fort, D.; Seoane, L. Hospitalization and mortality among black patients and white patients with Covid-19. N. Engl. J. Med. 2020, 382, 2534-2543. [CrossRef] [PubMed]

3. Patel, A.P.; Paranjpe, M.D.; Kathiresan, N.P.; Rivas, M.A.; Khera, A.V. Race, Socioeconomic deprivation, and hospitalization for COVID-19 in English participants of a National Biobank. medRxiv 2020. [CrossRef]

4. Rentsch, C.T.; Kidwai-Khan, F.; Tate, J.P.; Park, L.S.; King, J.T.; Skanderson, M.; Hauser, R.G.; Schultze, A.; Jarvis, C.I.; Holodniy, M.; et al. Covid-19 by race and ethnicity: A national cohort study of 6 million United States veterans. medRxiv 2020. [CrossRef]

5. Richardson, S.; Hirsch, J.S.; Narasimhan, M.; Crawford, J.M.; McGinn, T.; Davidson, K.W. And the Northwell COVID-19 Research Consortium. Presenting characteristics, comorbidities, and outcomes among 5700 patients hospitalized with COVID-19 in the New York City area. JAMA 2020, 10, 2052-2059. [CrossRef]

6. Grasselli, G.; Pesenti, A.; Cecconi, M. Critical Care utilization for the COVID-19 outbreak in Lombardy, Italy: Early experience and forecast during an emergency response. JAMA 2020, 323, 1545-1546. [CrossRef]

7. Lapostolle, F.; Goix, L.; Vianu, I.; Chanzy, E.; De Stefano, C.; Gorlicki, J.; Petrovic, T.; Adnet, F. COVID-19 epidemic in the Seine-Saint-Denis Department of Greater Paris: One month and three waves for a tsunami. Eur. J. Emerg. Med. 2020, 27, 274-278. [CrossRef] 
8. Pereira, I.G.; Guerin, J.M.; Silva Júnior, A.G.; Garcia, G.S.; Piscitelli, P.; Miani, A.; Distante, C.; Gonçalves, L.M.G. Forecasting Covid-19 dynamics in Brazil: A data driven approach. Int. J. Environ. Res. Public Health 2020, 17, 5115. [CrossRef]

9. Netea, M.G.; Joosten, L.A.; Latz, E.; Mills, K.H.; Natoli, G.; Stunnenberg, H.G.; O’Neill, L.A.; Xavier, R.J. Trained immunity: A program of innate immune memory in health and disease. Science 2016, 352, 6284. [CrossRef] [PubMed]

10. Sharma, A.R.; Batra, G.; Kumar, M.; Mishra, A.; Singla, R.; Singh, A.; Singh, R.S.; Medhi, B. BCG as a game-changer to prevent the infection and severity of COVID-19 pandemic? Allergol. Immunopathol. 2020. [CrossRef] [PubMed]

11. Koti, M.; Morales, A.; Graham, C.H.; Siemens, D.R. BCG vaccine and COVID-19: Implications for infection prophylaxis and cancer immunotherapy. J. Immunother. Cancer 2020, 8, e001119. [CrossRef] [PubMed]

12. Ebina-Shibuya, R.; Horita, N.; Namkoong, H.; Kaneko, T. National policies for paediatric universal BCG vaccination were associated with decreased mortality due to COVID-19. Respirology 2020. [CrossRef] [PubMed]

13. Curtis, N.; Sparrow, A.; Ghebreyesus, T.A.; Netea, M.G. Considering BCG Vaccination to reduce the impact of COVID-19. Lancet 2020, 395, 1545-1546. [CrossRef]

14. Netea, M.G.; Giamarellos-Bourboulis, E.J.; Domínguez-Andrés, J.; Curtis, N.; van Crevel, R.; van de Veerdonk, F.L.; Bonten, M. Trained immunity: A tool for reducing susceptibility to and the severity of SARS-CoV-2 infection. Cell 2020, 181, 969-977. [CrossRef]

15. O'Neill, L.A.J.; Netea, M.G. BCG-induced trained immunity: Can it offer protection against COVID-19? Nat. Rev. Immunol. 2020, 20, 335-337. [CrossRef]

16. Ozdemir, C.; Kucuksezer, U.C.; Tamay, Z.U. Is BCG vaccination affecting the spread and severity of COVID-19? Allergy 2020. [CrossRef]

17. Gursel, M.; Gursel, I. Is global BCG vaccination-induced trained immunity relevant to the progression of SARS-CoV-2 pandemic? Allergy 2020, 75, 1815-1819. [CrossRef]

18. Miyasaka, M. Is BCG vaccination causally related to reduced COVID-19 mortality? EMBO Mol. Med. 2020, 12, e12661. [CrossRef]

19. Coronavirus Update. Available online: https://www.worldometers.info/coronavirus/ (accessed on 17 July 2020).

20. World Population Clock. Available online: https://www.worldometers.info/world-population/ (accessed on 22 May 2020).

21. UN Data. A World of Information. Available online: https://data.un.org/ (accessed on 17 July 2020).

22. The BCG World Atlas. Available online: http://www.bcgatlas.org/index.php (accessed on 20 May 2020).

23. The Global Health Observatory. Available online: https://www.who.int/data/gho (accessed on 20 May 2020).

24. Kim, J.H. Multicollinearity and misleading statistical results. Korean J. Anesthesiol. 2019, 72, 558-569. [CrossRef]

25. Escobar, L.E.; Molina-Cruz, A.; Barillas-Mury, C. BCG vaccine protection from severe coronavirus disease 2019 (COVID-19). Proc. Natl. Acad. Sci. USA 2020, 117, 202008410. [CrossRef]

26. Weng, C.H.; Saal, A.; Butt, W.W.; Bica, N.; Fisher, J.Q.; Tao, J.; Chan, P.A. Bacillus Calmette-Guérin vaccination and clinical characteristics and outcomes of COVID-19 in Rhode Island, United States: A cohort study. Epidemiol. Infect. 2020, 148, e140. [CrossRef] [PubMed]

27. Klinger, D.; Blass, I.; Rappoport, N.; Linial, M. Significantly improved COVID-19 outcomes in countries with higher BCG vaccination coverage: A multivariable analysis. Vaccines 2020, 8, 378. [CrossRef] [PubMed]

28. Arts, R.J.W.; Moorlag, S.J.C.F.M.; Novakovic, B.; Li, Y.; Wang, S.Y.; Oosting, M.; Kumar, V.; Xavier, R.J.; Wijmenga, C.; Joosten, L.A.B.; et al. BCG vaccination protects against experimental viral infection in humans through the induction of cytokines associated with trained immunity. Cell Host Microbe 2018, 23, 89-100. [CrossRef] [PubMed]

29. Hisaka, A.; Yoshioka, H.; Hatakeyama, H.; Sato, H.; Onouchi, Y.; Anzai, N. Global comparison of changes in the number of test-positive cases and deaths by coronavirus infection (COVID-19) in the world. J. Clin. Med. 2020, 9, 1904. [CrossRef] 
30. Yates, T.; Razieh, C.; Zaccardi, F.; Davies, M.J.; Khunti, K. Obesity and risk of COVID-19: Analysis of UK biobank. Prim. Care Diabetes 2020. [CrossRef]

31. Ten Doesschate, T.; Moorlag, S.J.C.F.M.; van der Vaart, T.W.; Taks, E.; Debisarun, P.; Ten Oever, J.; Bleeker-Rovers, C.P.; Verhagen, P.B.; Lalmohamed, A.; Ter Heine, R.; et al. BCG-CORONA study team: Two randomized controlled trials of Bacillus Calmette-Guérin vaccination to reduce absenteeism among health care workers and hospital admission by elderly persons during the COVID-19 pandemic: A structured summary of the study protocols for two randomised controlled trials. Trials 2020, 21, 555. [CrossRef]

(C) 2020 by the authors. Licensee MDPI, Basel, Switzerland. This article is an open access article distributed under the terms and conditions of the Creative Commons Attribution (CC BY) license (http://creativecommons.org/licenses/by/4.0/). 